\title{
Condições de balneabilidade da cachoeira de Taquaruçu no distrito de Taquaruçu em Palmas/TO
}

A degradação do meio ambiente têm sido uns dos assuntos mais debatidos da atualidade, principalmente quando os problemas se tratam do desmatamento e da poluição da água. A poluição da água tem se tornado um grande problema para os atuais governantes, isso se deve principalmente a precária capacidade de gestão dos recursos hídricos e dos esgotos que são lançados muitas vezes in natura nos corpos d'água. A quantidade de água doce com o passar dos anos tem diminuído principalmente devido seu uso irracional, a qualidade das águas também tem sido afetada, causando enormes impactos para a vida marinha. Poluição dos recursos hídricos, disposição inadequada do esgoto, ausência de saneamento básico e de tratamento de esgoto inadequado, são alguns dos causadores de grandes impactos ambientais que têm afetado a saúde da população. É de grande importância social e ambiental haver estudos para atestar a capacidade de balneabilidade dos corpos hídricos, principalmente os que recebem grande número de pessoas. Prezar pela saúde dos usuários de contato primário é de grande importância para os órgãos de proteção ao meio ambiente, uma vez que a saúde de ambos (natureza e humana) devem ser preservadas. Em virtude dos fatos expostos, o presente trabalho avaliou a qualidade das águas da Cachoeira de Taquaruçu no distrito de Taquaruçu em Palmas/TO, proporcionando através de análise da balneabilidade do local. Verificar se a condição da água, está em acordo com a resolução cONAMA no 274/00, que estabelece os critérios mínimos de qualidade para utilização da água.

Palavras-chave: Balneabilidade; Qualidade de água; Coliformes fecais.

\section{Bathing conditions of the Taquaruçu waterfall in the district of Taquaruçu in Palmas/TO}

Degradation of the environment has been one of the most debated issues today, especially when the problems are deforestation and water pollution. Wate pollution has become a major problem for current governments, this is mainly due to the precarious capacity to manage water resources and sewage that are often released in nature into bodies of water. The amount of fresh water over the years has decreased mainly due to its irrational use, the quality of the water has also been affected, causing huge impacts on marine life. Pollution of water resources, inadequate sewage disposal, lack of basic sanitation and inadequate sewage treatment, are some of the causes of major environmental impacts that have affected the health of the population. It is of great social and environmental importance to have studies to certify the capacity of bathing water bodies, especially those that receive large numbers of people. Caring for the health of primary contact users is of great importance for environmental protection agencies, since the health of both (nature and human) must be preserved. Due to the exposed facts, the present work evaluated the water quality of the Taquaruçu Waterfall in the Taquaruçu district in Palmas/TO, providing through the analysis of the bathing of the place. Check if the condition of the water is in accordance with CONAMA resolution No. 274/00, which establishes the minimum quality criteria for water use.

Keywords: Bathing quality; Water quality; Fecal coliforms.

Topic: Engenharia de Recursos Hídricos

Reviewed anonymously in the process of blind peer.
Received: 09/07/2020

Approved: 21/10/2020
Jacqueline Lacerda Brito

Instituto Tocantinense Presidente Antônio Carlos, Brasil

jacquelinelacerdab01@outlook.com

Ângelo Ricardo Balduino (D)

Instituto Tocantinense Presidente Antônio Carlos, Brasil

http://lattes.cnpq.br/8475669590774317

http://orcid.org/0000-0002-7082-2566

angelo@ifto.edu.br
Referencing this:

BRTIO, J. L.; BALDUINO, A. R.. Condições de balneabilidade da cachoeira de Taquaruçu no distrito de Taquaruçu em Palmas/TO. Natural Resources, v.10, n.3, p.60-67, 2020. DOI: http://doi.org/10.6008/CBPC2237-9290.2020.003.0007 


\section{INTRODUÇÃO}

A água é conhecida como sendo uma substância de grande importância para a natureza há milênios, e exerce papel fundamental para a preservação dos ecossistemas e da vida dos seres vivos. A sobrevivência de plantas, animais e demais seres vivos depende da estrutura e das funções de um meio ambiente (WOLKMER et al., 2013).

Heller et al. (2010) dizem que, com relação aos diversos usos dos recursos hídricos demandados pela população e pelas atividades econômicas, alguns apresentam perdas entre o volume de água captado e o volume que retorna ao curso de água (usos consuntivos - abastecimento doméstico e industrial, irrigação, aquicultura) e outros que não se verificam perdas (usos não consuntivos - geração de energia hidroelétrica, navegação, recreação, pesca, diluição, assimilação e afastamento de efluentes).

Ao longo dos anos as mudanças ocorridas pelo ecossistema aquático têm se alastrado em diferentes graus. Tais mudanças são resultados da evolução da humanidade que facilitou em boa parte do planeta o acesso à água ao longo dos anos, gerando um aumento do seu uso, isso tem ocasionado destruições muitas vezes inconvertíveis como a diminuição significativa da quantidade de água de qualidade (PEREIRA, 2005).

Segundo Tucci et al. (2000), "o desenvolvimento dos recursos hídricos e a preservação dos sistemas naturais estão relacionados às condições sociais e econômicas do país, e representam um enorme desafio para a população brasileira". Segundo Goulart et al. (2003), o reconhecimento das alterações ambientais presentes no ecossistema aquático é feito por meio do estudo e mensuração de mudanças na aglomeração de variáveis físicas, químicas e microbiológicas. Observar os indicadores e fazer o monitoramento é importante para acompanhar determinadas características de um sistema.

Segundo Fujioka (1997), a necessidade de se determinar quando um corpo d'água está contaminado por esgotos já era conhecida desde que doenças clássicas oriundas da ingestão de água contaminada eram tratadas e a causa apontava sempre para os esgotos como fonte dessas doenças, mas os métodos de detecção de várias bactérias eram precários e os isolamentos de alguns patógenos na água não eram possíveis. É de grande importância para promover a saúde pública obter a relação entre a existência de indicadores de poluição fecal no ambiente aquático e a ameaça potencial de adquirir doenças graves por meio da utilização da água para recreação (CETESB, 2004).

Para haver uma avaliação da balneabilidade é necessário que se estabeleça critérios objetivos para águas com fins de recreação de contato primário. Microrganismos indicadores de contaminação fecal são utilizados como critérios a serem monitorados e seus valores confrontados com padrões preestabelecidos, podendo assim haver a identificação das condições de balneabilidade em um determinado local. Para uma melhor recomendação aos banhistas, podem-se definir, inclusive, classes de balneabilidade (CETESB, 2015).

Segundo Cordeiro (2005), a poluição aquática pode acontecer de forma física, química e biológica. A poluição física ocorre através do descarte de material sólido (minerais ou orgânicos em variados tamanhos ou totalmente dissolvidos). A poluição química ocorre através da carência de oxigênio, toxidez e eutrofização. Essa poluição pode se caracterizar como orgânica (lixos, esgoto doméstico, combustíveis fósseis e outros 
resíduos em processo de decomposição) e inorgânica (substâncias solubilizadas como iodo, mercúrio, cobre, níquel e outros durante práticas industriais, urbanas, agropecuárias ou de mineração). Já a poluição biológica dos recursos hídricos se caracteriza pela assiduidade de organismos na água, como bactérias, fungos, vírus e algas, protozoários, elementos geradores de doenças em homens e também em animais.

A contaminação do esgoto doméstico lançado em corpos hídricos, ao atingirem as águas das praias podem expor os banhistas a microrganismos patogênicos, como vírus, bactérias, fungos, protozoários patogênicos e ovos de helmintos. Após o banho em águas contaminadas, os mais propícios a desenvolver doenças ou infecções são crianças, idosos ou pessoas com baixa resistência (CETESB, 2015).

De acordo com a CETESB (2015), do ponto de vista de saúde pública, deve ser levado em consideração tanto a transmissão de doenças de veiculação hídrica aos banhistas (gastroenterite, hepatite A, cólera, febre tifoide, entre outras), como também a ocorrência de organismos patogênicos, responsáveis por dermatoses e outras doenças não afetas ao trato intestinal (conjuntivite, otite e doenças das vias respiratórias). No geral as doenças relacionadas ao banho não requerem tratamento, se necessário respondem rapidamente ao tratamento e não possuem efeitos de longo prazo na saúde das pessoas. A doença mais comum associada à água poluída por esgotos é a gastroenterite, que pode aparecer com um ou mais dos seguintes sintomas: enjoo, vômitos, dores abdominais, dor de cabeça e febre, sendo a diarreia o sintoma mais frequente.

Taquaruçu é um distrito da capital Palmas/TO, famosa pelas cachoeiras presentes na Bacia do Ribeirão do Taquaruçu, contando com mais de 80 cachoeiras catalogadas, uma delas é a cachoeira de Taquaruçu, que é o local analisado nesse estudo. Com a popularização das quedas d'água que rodeiam o distrito, o número de turistas naquela região tem se tornado cada vez maior, proporcionando ao distrito melhor desenvolvimento econômico, trazendo mais oportunidades de geração de recursos e da melhoria da vida local, preservando o meio ambiente e a cultura. Nesse contexto, o presente estudo buscou determinar a qualidade da água em um ponto da cachoeira de Taquaruçu que serve para fins de balneabilidade.

\section{METODOLOGIA}

A pesquisa foi baseada em estudo de caso para avaliar as condições da água da cachoeira de Taquaruçu para fins de balneabilidade, como forma de diagnosticar a situação atual, realizando a análise da água através de exames microbiológicos, de acordo com os métodos descritos em Standard Methods (APHA, 2005).

\section{Área de estudo}

O local escolhido para realização dessa pesquisa foi a cachoeira de Taquaruçu, situada no distrito de Taquaruçu do munício de Palmas/TO, que é formada pela queda d'água da Bacia do Ribeirão do Taquaruçu. O local possui apenas um restaurante com pouca estrutura, servindo como principal ponto de suporte para os visitantes. A região representa uma área de importante preservação, pois abriga diferentes tipos de biomas (cerrado, caatinga, pantanal e floresta amazônica). A região de Taquaruçu é um dos principais atrativos turísticos do estado do Tocantins e têm grande potencial de desenvolvimento. A figura 1 apresenta 
a cachoeira de Taquaruçu, local da realização do estudo.

Segundo o IBGE (2019), a população estimada da capital Palmas é de 299.127 habitantes, porém segundo um senso de 2010 aproximadamente 4.800 habitantes residem no distrito de Taquaruçu, que se localiza a $32 \mathrm{~km}$ do centro da capital.

A cachoeira de Taquaruçu situa-se na bacia hidrográfica do Ribeirão Taquaruçu Grande, e está localizada entre os paralelos $10^{\circ} 18^{\prime} 20^{\prime \prime}$ e $10^{\circ} 18^{\prime} 20^{\prime \prime}$ de latitude sul e entre os meridianos $48^{\circ} 11^{\prime} 20^{\prime \prime}$ e $48^{\circ} 11^{\prime} 17^{\prime \prime}$ de longitude oeste, estando localizado a nordeste do distrito de Taquaruçu. A Figura 2 apresenta a localização da cachoeira no distrito de Taquaruçu, Palmas - TO.

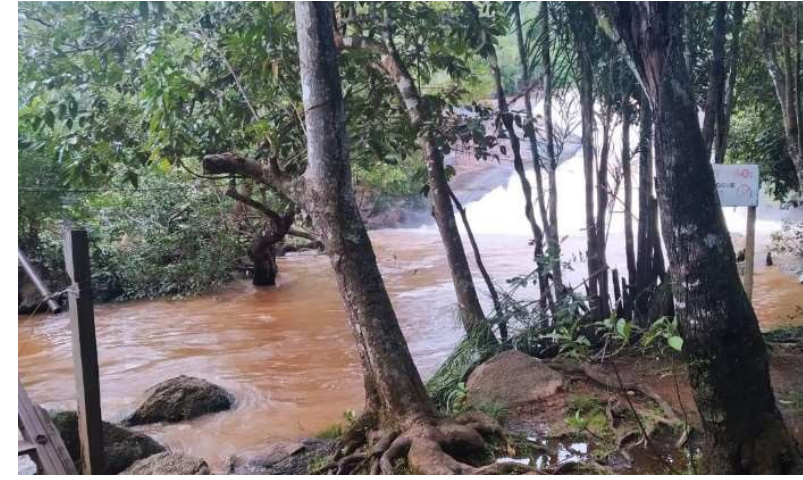

Figura 1: Cachoeira de Taquaruçu.

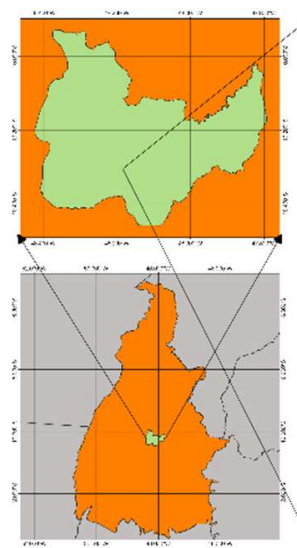

Figura 2: Localização da Cachoeira de Taquaruçu. Fonte: SEFAZ (2019).

\section{Procedimento de campo}

A Resolução CONAMA no 274/00 recomenda que a amostragem seja efetuada em local que apresentar a isóbata de um metro e onde houver maior concentração de banhistas. A partir disso, um ponto é selecionado com o auxílio do aparelho GPS constando ZONA, DATUM e coordenadas.

A metodologia utilizada em campo para coleta das amostras seguiu as especificações técnica da NBR 9897 que trata o planejamento da amostragem de efluentes líquidos e corpos receptores, onde as coletas das amostras de água para análise aconteceu semanalmente durante o período de seis semanas, entre os meses de fevereiro a março de 2020 , utilizando recipientes de $100 \mathrm{ml}$ para as amostras microbiológicas; e também da NBR 9898 para a preservação e técnicas de amostragem de efluentes líquidos e corpos receptores, sendo que logo após feita a coleta, as amostras foram etiquetados e acondicionadas em caixas térmicas contendo gelo e levadas para serem processadas no laboratório de química do IFTO - Instituto Federal de Educação, Ciência e Tecnologia do Tocantins, em Porto Nacional.

O ponto de coleta de água foi selecionado de acordo com o local de maior utilização pelos banhistas, conforme recomendado no Art. 5ำ, parágrafo único, da Resolução Conama no 274/00.

\section{Metodologia laboratorial}

Para avaliar a balneabilidade da Cachoeira de Taquaruçu, foram utilizadas as bactérias do grupo coliformes fecais como parâmetro indicador microbiológico de qualidade da água de acordo com o método 
Collilert segundo a metodologia descrita por Standard Methods (APHA, 2005).

Para essa pesquisa foi utilizado o método de Collilert, no qual o meio de cultura (enzima Collilert) já chega com a quantidade certa para a análise de $100 \mathrm{ml}$ de água. Logo após cada enzima é adicionado ao frasco de $100 \mathrm{ml}$ que contém a amostra de água, que é agitada até os grânulos se diluírem totalmente. Após isso, a solução é incubada a 35ㄷ em estufa por 24 horas. A Resolução CONAMA 274/2000 foi quem determinou os parâmetros que foram seguidos, estabelecendo os métodos de análise, sendo os coliformes fecais o indicador microbiológico de balneabilidade.

\section{RESULTADO E DISCUSSÃO}

A balneabilidade é a análise da qualidade das águas destinadas à recreação de contato primário, no qual há um contato direto e prolongado com a água (natação, mergulho, esqui aquático etc.), havendo a possibilidade elevada de ingerir quantidade estimável de água. Para a realização da análise é necessário se basear em indicadores supervisionados, comparando os resultados com os presentes em normativas que regulamentam a qualidade da água (BRASIL, 2000).

A presença de indicadores microbiológicos de poluição fecal na água está diretamente relacionada com o risco potencial de se contrair doenças infecciosas no uso para recreação. Tais critérios são importantes para manter a saúde, segurança e bem-estar da população (CETESB, 2015).

Segundo a Resolução do CONAMA № 274/00, a principal característica que constata a balneabilidade de uma praia é a análise feita que qualifica se a água possui qualidade excelente, muito boa ou satisfatória caso obtenha baixos níveis de coliformes fecais nas análises laboratoriais. A água ainda pode ser classificada como imprópria, havendo a possibilidade de interdição de trechos, caso os órgãos de controle ambiental constatem que a água de contato primária é de má qualidade.

É de grande importância para promover a saúde pública obter a relação entre a existência de indicadores de poluição fecal no ambiente aquático e a ameaça potencial de adquirir doenças graves por meio da utilização da água para recreação (CETESB, 2004).

De acordo com o CONAMA (2000), é importante destacar o segundo artigo da Resolução 274 que define as condições de avaliação nas categorias própria e imprópria:

$\S 1$ As águas consideradas próprias poderão ser subdivididas nas seguintes categorias:

Excelente: quando em $80 \%$ ou mais de um conjunto de amostras obtidas em cada uma das cinco semanas anteriores, colhidas no mesmo local, houver, no máximo, 250 coliformes fecais (termotolerantes) ou 200 Escherichia coli ou 25 enterococos por 100 mililitros;

Muito Boa: quando em $80 \%$ ou mais de um conjunto de amostras obtidas em cada uma das cinco semanas anteriores, colhidas no mesmo local, houver, no máximo, 500 coliformes fecais (termotolerantes) ou 400 Escherichia coli ou 50 enterococos por 100 mililitros;

Satisfatória: quando em $80 \%$ ou mais de um conjunto de amostras obtidas em cada uma das cinco semanas anteriores, colhidas no mesmo local, houver, no máximo 1.000 coliformes fecais (termotolerantes) ou 800 Escherichia coli ou 100 enterococos por 100 mililitros.

$\S 4$ 을 águas serão consideradas IMPRÓPRIAS quando no trecho avaliado, for verificada uma das seguintes ocorrências:

a) Não atendimento aos critérios estabelecidos para as águas próprias; 
b) Valor obtido na última amostragem for superior a 2.500 coliformes fecais (termotolerantes) ou 2.000 Escherichia coli ou 400 enterococos por 100 mililitros;

c) Incidência elevada ou anormal, na região de coleta, de enfermidades transmissíveis por via hídrica, indicada pelas autoridades sanitárias;

d) Presença de resíduos ou despejos sólidos ou líquidos, inclusive esgotos sanitários, óleos, graxas e outras substâncias capazes de oferecer riscos à saúde ou tornar desagradável a recreação;

e) $\mathrm{pH}<6,0$ ou pH > 9,0 (águas doces), à exceção das condições naturais;

f) Floração de algas ou outros organismos, até que se comprove que não oferecem riscos à saúde humana;

g) Outros fatores que contraindiquem, temporária ou permanentemente, o exercício da recreação de contato primário;

O quadro 1 apresenta a classificação da água em relação à balneabilidade de acordo com a Resolução $274 / 2000$.

Quadro 1: Classificação da água em relação à balneabilidade segundo a Resolução 274.

\begin{tabular}{|l|l|l|}
\hline Categoria & Coliformes fecais (NMP/100ml) * & Escherichia Coli (NMP/100ml) * \\
\hline Excelente & $<250$ & $<200$ \\
\hline Muito Boa & $<500$ & $<400$ \\
\hline Satisfatória & $<1000$ & $<800$ \\
\hline Imprópria & Acima de 2500 & Acima de 2000 \\
\hline
\end{tabular}

*NMP: Número mais provável por $100 \mathrm{ml}$., em $80 \%$ ou mais de um conjunto de amostras obtidas em cada uma das cinco semanas anteriores. Fonte: Resolução № 274/2000 do CONAMA.

O artigo terceiro a Resolução 274/2000 disserta sobre a interdição de trechos das praias e balneários, que acontecerá caso seja constatado pelo órgão de controle ambiental, em qualquer das suas instâncias, que a má qualidade das águas de recreação de contato primário justifica a medida. São passiveis de interdição os trechos que ocorram acidentes de médio e grande porte, tais como: derramamento de óleo e extravasamento de esgoto, a ocorrência de toxicidade ou formação de nata decorrente de floração de algas ou outros organismos e, no caso de águas doces, a presença de moluscos transmissores potenciais de esquistossomose e outras doenças de veiculação hídrica.

Dessa forma, os órgãos de controle ambiental sejam no âmbito municipal, estadual ou federal, tem atribuído em suas responsabilidades fazer a divulgação das condições de balneabilidade das praias e dos balneários, além de serem responsáveis pela inspeção da aplicação e cumprimento da Resolução 274/00 (CONAMA, 2000).

Visto isso, a atual pesquisa foi embasada nos critérios de classificação da Resolução CONANA 274/2000, onde os resultados obtidos a partir das análises das coletas durante as seis semanas consecutivas, nos meses fevereiro e março, foram apresentados e discutidos por meio dos indicadores de Coliformes Totais e E. Coli, podendo definir se as águas são próprias ou impróprias para fins de balneabilidade.

Os resultados obtidos com as análises foram um tanto discrepantes, tendo um intervalo muito grande entre as seis amostras analisadas, apresentando valor máximo de 2419,6 NMP/100 Ml e mínimo de 263,1 NMP/100 MI de E. Coli. Em todas as amostras analisadas foi constatada a presença a presença de coliformes totais.

Durante o período de monitoramento da Cachoeira de Taquaruçu, foi constatada a presença de 
Coliformes Fecais em todas as análises logo após as amostras serem submetidas à presença de luz ultravioleta a $365 \mathrm{~nm}$, tendo sido observada as características de fluorescência e foi encontrado um valor médio da bactéria Escherichia coli de 688,2 NMP/100 Ml, se enquadrando como satisfatória segundo a Resolução do CONAMA 274/00, sendo o valor para ser considerado nessa classe deve estar na faixa dos $400 \mathrm{NMP} / 100 \mathrm{MI}$ a $800 \mathrm{NMP} / 100 \mathrm{Ml}$, para fins de balneabilidade.

Dessa forma, a água da cachoeira no ponto analisado está classificada como satisfatória, devendo está em alerta com o período chuvoso, pois a $3^{a}$ coleta apresentou valor superior a $2000 \mathrm{NMP} / 100 \mathrm{Ml}$, podendo ser indicativo de um provável problema com o descarte do esgoto produzido no restaurante que serve como ponto de apoio do turista no local.

Durante o período analisado a concentração de visitantes e banhistas na cachoeira de Taquaruçu era pequena, devido à época de chuva e os dias das coletas realizas serem durante a semana, sendo que os finais de semana é quando o turismo é mais forte. Apesar de ser um local afastado, a alta concentração da bactéria Escherichia coli presente na água se deve principalmente ao período chuvoso, que faz o carreamento dos resíduos sólidos através do escoamento superficial da água da chuva, podendo haver uma possível contaminação do solo por resíduos sólidos, fezes de animais de sangue quente, fossas privadas e ausência de rede de esgoto. Estes efluentes causam alterações da qualidade da água do corpo hídrico para fins de balneabilidade.

\section{CONCLUSÕES}

Os resultados obtidos a partir desta pesquisa serviram de grande relevância para avaliar as condições de qualidade da água da cachoeira de Taquaruçu, local com o uso destinado a balneabilidade. Haver um monitoramento contínuo contribui para que haja mais atenção quanto aos cuidados e riscos relacionados à contaminação das águas, servindo como um aviso para os órgãos competentes e também para a população.

Através de indicadores de poluição fecal, como as bactérias do grupo coliformes fecais e $E$. coli, foi possível fazer as análises laboratoriais, obtendo os resultados que foram analisados. As análises seguiram de acordo com a Resolução CONAMA 274/2000, que enquadra o resultado em suas categorias.

Os resultados obtidos mostraram que as águas da cachoeira de Taquaruçu no ponto analisado, se enquadra como satisfatória, levando a ser considerado a realização de mais estudos para que possa ser analisado a qualidade em outros pontos, podendo assim obter maiores resultados e possíveis fontes de contaminação. Medidas de caráter preventivas são de grande necessidade, devido ter apresentado valor alto em uma das análises, podendo ser indicativo de uma contaminação recente.

Vale ressaltar que as coletas para o estudo foram feitas em baixa temporada devido à época de chuvas, tais resultados podem apresentar piora com grandes concentrações de turistas no local, como já é de costume. É necessária a presença de órgãos de controle ambiental no local, para que solicite e apoie medidas preventivas.

Alguma das medidas que devem começar a ser utilizadas para retardar o avanço da poluição nessa bacia hidrográfica é adotar regras para o uso dos visitantes, além de realizar trabalho de limpeza nas margens 
da cachoeira periodicamente a fim de evitar o carreamento para a cachoeira no período chuvoso. Há a presença de um único comércio, que deve seguir padrões melhores para o tratamento e descarte do esgoto doméstico. A implantação de placas informando sobre a atual condição das águas da cachoeira é uma medida de suma importância que deveria ser adotada pelos órgãos de controle ambiental.

Dessa forma, fica exposta a importância de haver um monitoramento dos recursos hídricos, principalmente para aqueles com fins de balneabilidade, pois há um contato direto dos banhistas. É evidente a necessidade das Secretarias Estadual e Municipal de Meio Ambiente, criar parcerias com Instituições Acadêmicas, para que estudos como este se tornem mais frequente e possa ser desenvolvido em conjunto estratégia para a preservação dos corpos hídricos.

\section{REFERÊNCIAS}

APHA. American Public Health Association. Standard methods for the examination ofwater and watwater. $21 \mathrm{ed}$. Washington: APHA, 2005.

BRASIL. Resolução CONAMA n. 274, de 29 de novembro de 2000. Brasília: DOU, 2001.

CETESB. Companhia de Tecnologia de Saneamento Ambiental. Relatório de Qualidade das Águas Litorâneas no Estado de São Paulo: Balneabilidade das Praias. São Paulo: CETESB, 2004.

CETESB. Companhia de Tecnologia de Saneamento Ambiental. Qualidade das praias litorâneas no estado de São Paulo. São Paulo: CETESB, 2015.

CONAMA. Conselho Nacional Do Meio Ambiente. Resolução n. 274 de 29 de novembro de 2000: Define os critérios de balneabilidade em águas brasileiras. Brasília: DOU, 2000.

CORDEIRO, A. M. T. M.. Gestão dos recursos hídricos no Brasil do ponto de vista legal. Uninorte Faculdade de Direito, 2005
FUJIOKA, R. S.. Indicators of marine recreational water quality. Washington, 1997.

GOULART, M. D. C.; CALLISTO, M.. Bioindicadores de qualidade de água como ferramenta em estudos de impacto ambiental. Revista da FAPAM, v.2, n.1, 2003.

HELLER, L.; PÁDUA, V. L.. Abastecimento de água para o consumo humano. 2 ed. Belo Horizonte: UFMG, 2010.

PEREIRA, R. S.. Poluição hídrica: causas e consequências. Porto Alegre: Universidade Federal do Rio Grande do Sul, 2005.

TUCCI, C. E. M.; HESPANHOL, I.; NETTO, O. M. C.. Cenários da gestão da água no Brasil: Uma contribuição para a "visão mundial da água". Revista Brasileira de Recursos Hídricos, v.5, n.3, 2000.

WOLKMER, M. F. S.; PIMMEL, N. F.. Política nacional de recursos hídricos: governança água e cidadania ambiental. Revista Sequência, Florianópolis, v.34, n.67, 2013. DOI: https://doi.org/10.5007/2177-7055.2013v34n67p165

A CBPC - Companhia Brasileira de Produção Científica (CNPJ: 11.221.422/0001-03) detém os direitos materiais desta publicação. Os direitos referem-se à publicação do trabalho em qualquer parte do mundo, incluindo os direitos às renovações, expansões e disseminações da contribuição, bem como outros direitos subsidiários. Todos os trabalhos publicados eletronicamente poderão posteriormente ser publicados em coletâneas impressas sob coordenação da Sustenere Publishing, da Companhia Brasileira de Produção Científica e seus parceiros autorizados. Os (as) autores (as) preservam os direitos autorais, mas não têm permissão para a publicação da contribuição em outro meio, impresso ou digital, em português ou em tradução. 